Research Article

\title{
Application of Mobile APP in Moral Education Course Teaching Based on Intelligent Internet of Things
}

\author{
Guoyong Liu' ${ }^{1}$ and Yongjie $\mathrm{Xu} \mathbb{1 D}^{2}$ \\ ${ }^{1}$ Xi'an Fanyi University, Xi'an 710105, Shaanxi, China \\ ${ }^{2}$ Computer Application Research Center of Hunan University of Applied Technology, Changde 415000, Hunan, China
}

Correspondence should be addressed to Yongjie Xu; 20150307@stu.nun.edu.cn

Received 30 August 2021; Revised 11 October 2021; Accepted 18 October 2021; Published 24 November 2021

Academic Editor: Sang-Bing Tsai

Copyright (c) 2021 Guoyong Liu and Yongjie Xu. This is an open access article distributed under the Creative Commons Attribution License, which permits unrestricted use, distribution, and reproduction in any medium, provided the original work is properly cited.

\begin{abstract}
Moral education is one of the important teaching goals of modern education. It is not a clear, specific, and microexamination teaching like knowledge and science but a political, ideological, and moral education in the form of curriculum teaching. In the information age, the Internet is filled with a huge amount of good and bad information. Facing the temptation and impact of bad information, moral education is very important. The main purpose of this research is to understand the current status of moral education curriculum teaching in China and propose a method of applying mobile APP to assist moral education curriculum teaching in accordance with the development difficulties faced by moral education curriculum teaching in the Internet era. This article uses the methods of literature research and questionnaire survey, by consulting the relevant literature and interviewing randomly selected teachers and students of moral education courses in secondary vocational colleges, from the basic conditions of students' academic qualifications and age, moral education course learning situation, and moral education course teaching arrangements and conducts questionnaire surveys on mobile APP teaching applications. Finally, this article also uses statistical methods to analyze the difficulties and impacts of moral education curriculum teaching and tests the effectiveness of the application of mobile APP teaching methods in moral education teaching through the independent sample $t$-test method. Research shows that at the level of significance of $\alpha=0.05$, the application of mobile APP does help to improve the learning efficiency and enthusiasm of students in the teaching of moral education courses and improve the teaching level of moral education courses.
\end{abstract}

\section{Introduction}

1.1. Background and Significance. In today's society, with the development of economy and the advancement of information technology, the application of mobile terminals has penetrated people's lives. While the Internet has brought convenience to people's communication and communication, it is also facing many crises and challenges, such as cyber violence and other bad influence incidents. Therefore, the ideological and moral construction of the new era is very important. After the 18th National Congress of the Communist Party of China, the party and the country have paid more attention to the teaching of moral education courses in secondary vocational colleges and even primary schools [1].
The development of mobile applications has had a huge impact on the classroom teaching styles of various courses. Nowadays, various stages of course teaching have begun to try to use mobile APP to assist classroom teaching, especially extracurricular course teaching [2]. The application of mobile APP is a double-edged sword for course teaching. While providing some convenience for the teaching of moral education courses in secondary vocational colleges, it is also easy for students to rely on mobile terminal products such as mobile phones or even indulge in it. However, the development and progress brought by mobile APP to the teaching of moral education courses cannot be ignored. Nowadays, bringing mobile phones into the classroom has become an unstoppable trend in classroom teaching [3]. Although 
domestic secondary vocational colleges still pay more attention to the traditional classroom teaching mode of book teaching and teachers' precepts and deeds, the application of mobile APP has had a great impact on this form of classroom teaching. In particular, the teaching of moral education courses is not a knowledge subject but is extremely important. Therefore, the traditional book teaching effect is extremely limited, and the teaching arrangement cannot arrange enough class hours. Therefore, the application of mobile APP brings new opportunities to solve this teaching problem. [4].

1.2. Related Research at Home and Abroad. For the application of mobile APP in classroom teaching, there are many research results at home and abroad. For example, Ponte, a foreign education scholar, discussed how to use mobile instant messaging tools (WhatsApp) to support the teaching of higher education courses, and the results showed that students expressed positive views and acceptance attitudes towards the mobile application of WhatsApp [5]. Unfortunately, the application research of this mobile APP in other academic environments has not been in-depth. Pereira proposed to use FLApp to provide a new method of teaching formal language and automata (FLA) courses for students, to provide students with answers to questions about regular, noncontextual, context-sensitive, and recursive enumerable languages, and to provide an educational environment. The learning process of each step of the algorithm that supports student learning is described and explained [6]. Landicho created gamified applications on the web and mobile devices to inspire and attract students to study courses in specific subjects. The basic functions of the application include merging courses, creating syllabus, and integrating specification sheets, which distinguish it from other existing gamification applications. Research has found that the application is quite effective in improving students' learning enthusiasm [7]. Turkan et al. proposed a new teaching method that combines mobile augmented reality (AR) and interactive $3 \mathrm{D}$ visualization technology for teaching structural analysis and enhances structural analysis textbooks and worksheets by visualizing discrete structural components using AR and interactive 3D models. The content is used to explain the behavior of the structure under different load conditions [8]. Klímová explored the use of smartphones and their applications in teaching foreign languages. The results show that the use of smartphones and their applications has a positive impact on students' foreign language learning, especially in the development of students' vocabulary and their motivation to learn [9].

The application of mobile APP in domestic classroom teaching is also developing rapidly. For example, as the most representative figure in this field in China, Cao has found that it is feasible to use smartphones as a classroom teaching tool through his experience in classroom teaching in other countries during his one-year study abroad [10]. However, there are still many controversies in this view. Wang et al. proposed to establish a WeChat official account (OA) as an instant interactive platform to provide students with more frequent feedback and guidance and to promote better student-centered communication in the teaching process [11]. However, the proposal has not been widely adopted. Based on the development of multimedia information, Zhang has studied the development of educational technology from traditional teaching, ordinary media technology to computer technology and communication technology, and proposed the design and research of the mobile English teaching system framework based on android platform [12]. However, the results are not significant due to the immature technology. Gao C established a mobile digital map teaching system to explore effective mobile terminal learning models. The results show that the WeChat official account management platform has played an active role in attracting learners, disseminating microcontent, promoting personalized learning, and evaluating real-time learning effects [13]. Xu and Wang studied the advantages and challenges brought by the new mobile teaching mode (MosoTeach) for students' English in the mobile Internet era [14]. The fly in the ointment is that the study did not specifically show the effectiveness of mobile APP in classroom teaching. However, the production of teaching APP is not mature and sophisticated enough and need to provide higher quality and better interactive education APP resources. The content and depth of the course, the determination and adaptation of students' learning methods, and so on must be able to better meet the needs of students. These are the next tasks.

1.3. Innovations in This Article. This article mainly studies the application of mobile APP in moral education curriculum teaching in the Internet age. Compared with traditional moral education curriculum teaching methods, the application of mobile APP can effectively enhance the interest of moral education curriculum teaching and thus improve students' enthusiasm for moral education curriculum learning. In the application of the moral education curriculum teaching APP, you can also add intelligent functions such as interest model and behavior monitoring and intelligent learning reminders to supervise students' learning. Multimedia teaching software is a computer teaching program designed according to teaching objectives, expressing specific teaching content, and reflecting certain teaching strategies. It can be used to store, transmit, and process teaching information, allowing students to interact and learn about teaching media for evaluation. In the analysis of the effectiveness of mobile APP on moral education curriculum teaching, this paper also verifies the influence of mobile APP on moral education curriculum teaching through independent sample $t$-tests, which makes the conclusions of this research more accurate.

\section{Application of Mobile APP in Moral Education Course Teaching}

2.1. Action Learning Method of Moral Education Course Teaching. Education is an important cornerstone for the development of human history and the inheritance of 
civilization. Since the imperial examination in our country, the concept of classroom teaching has begun to enter people's sight. No matter what kind of subject curriculum teaching is, it is inseparable from the new teaching methods developed by countless educational scholars. At present, in the classroom teaching of various subjects, the more famous teaching methods include activity teaching method and action learning method. In the Internet age, the teaching mode of mobile learning is also proposed [15-17]. This article mainly discusses the application of mobile APP in the teaching of moral education based on the ideas of the action learning method and mobile teaching mode. Although the early action learning method has no clear definition, its main idea is that learning is the process of acquiring procedural knowledge and asking insightful questions [18]. In short, it is learning through practice. This concept is similar to the important guiding ideology of "practice is the only criterion for testing truth." Its main connotation can be presented by the following formula:
$L=P+Q$, learning = programmed knowledge + question insight.

In the main content of formula (1) action learning method, Revens believed that insightful questioning is the focus of action learning, while the acquisition of procedural knowledge is only the goal and motivation of learning. The foundation of action learning is to rely on practical actions. It is insightful questioning, so Revans is called "the father of action learning" $[19,20]$. In the continuous development of curriculum teaching, action learning has also been applied to the classroom teaching of various knowledge subjects, and some educational scholars have enriched and reinterpreted the connotation of action learning. The connotation of the new action learning method can be expressed by the following formula:

$$
L=P+Q+R \text {, learning = programmed knowledge }+ \text { question insight }+ \text { reflection summary } .
$$

In the connotation expression formula of the new action learning method, $L$ represents learning, $P$ represents the acquisition process of procedural knowledge or operational knowledge, and $Q$ represents insightful questioning, which is action practice. Compared with the previous action learning method, the new action learning method expands the process of summary reflection, which is represented by $R$ in formula (2). A lot of practice has proved that timely summary and reflection in the course teaching cannot be ignored in the course learning.

\subsection{Survey and Statistics on the Current Teaching Situation of} Moral Education Courses. In order to deeply understand the current status of students' moral education courses in vocational colleges, this article collects the understanding and attitudes of teachers and students of vocational colleges and universities on the application of mobile APP in the teaching of moral education courses through questionnaire surveys and online surveys. Through the collected situation data, this article analyzes the current difficulties faced in the teaching of moral education courses in secondary vocational colleges and traces the reasons for these problems. In the process of processing and analyzing these data, this article uses several parameter estimation methods in statistics to analyze the correlation and regular characteristics between various influencing factors and experimental results more intuitively and reliably. Parameter estimation methods mainly include point estimation, moment estimation, and maximum likelihood estimation [21].

This article makes a maximum likelihood estimation based on the various teaching methods and class schedules in the teaching of moral education courses in secondary vocational colleges and the survey data of students' moral education courses under these teaching methods. Probability and statistics are used to analyze the advantages and disadvantages of these teaching methods and the application of mobile APP for moral education courses [22]. In the collected data, there are both discrete sample data such as student's moral education course scores and continuous data. In a random experiment, if an event occurs, assume that a parameter $\theta$ is the one with the largest probability of the event among all possible conditions in the experiment. Parameter estimation is to select the estimated value of this parameter $\theta$ through statistical data estimation. For discrete sample data, according to the probability of each part obtained by the total probability formula, the likelihood function of parameter $\theta$ can be obtained as shown in the following formula:

$$
L(\theta)=L\left(x_{1}, \ldots x_{n} ; \theta\right)=\prod_{i=1}^{n} p\left(x_{i} ; \theta\right) .
$$

Formula (3) is the joint distribution law of the sample population with the sample size $n$ where $p\left(x_{i} ; \theta\right)$ represents the probability of the value of condition $x_{i}$ under parameter $\theta$. For continuous random variable data, the likelihood function of parameter $\theta$ is similar to this, and the right side of the equation is the joint probability density function of the sample [23]. Its likelihood function is shown in the following equation:

$$
L(\theta)=L\left(x_{1}, \ldots x_{n} ; \theta\right)=\prod_{i=1}^{n} f\left(x_{i} ; \theta\right) .
$$

In the above formula, $f\left(x_{i} ; \theta\right)$ represents the probability density function of continuous random variable under parameter $\theta$. In parameter estimation, according to the needs of actual problems, sometimes the value of the parameter is not estimated directly but it is assumed that the parameter $\theta$ in the sample population $X$ obeys a certain distribution and in turn estimates the probability of the value 
of a certain condition $\hat{x}$, which is Bayesian estimate. The joint probability distribution of Bayesian estimation is shown in the following formula:

$$
p(\hat{x} \mid X)=\int_{\theta \in \Omega} p(\hat{x} \mid \theta) p(\theta \mid X) \mathrm{d} \theta=\int_{\theta \in \Omega} p(\hat{x} \mid \theta) \frac{p(\theta) p(X \mid \theta)}{p(X)} \mathrm{d} \theta .
$$

\subsection{Intelligent Internet of Things Application in Moral Edu-} cation Course Teaching. Regarding the application of mobile APP in the teaching of moral education courses, this article also proposes that the combination of intelligent Internet of Things technology enables mobile APP to play a greater role in course teaching. Although the learning of moral education courses is mainly carried out in the form of classroom teaching, learning outside the classroom cannot be ignored $[24,25]$. Based on this, behavior detection can be performed in classrooms and public places where privacy is not touched by student activities outside the classroom. This can be achieved only with the help of intelligent monitoring without additional resources and costs. The only function that this article needs to achieve is to collect and analyze the behavior detection results through the intelligent Internet of Things and then reflect to the students through the mobile APP and put forward some learning suggestions. Among them, the behavior detection technology principle of the intelligent Internet of Things is mainly the realization of intelligent image recognition, and its theoretical method is the extraction of feature values. As shown in formula (6), the image gradient feature extraction method mainly divides the image into several small pixel intervals, which can also be regarded as several small units. A coordinate system is established at the same position in these small cells, where $G_{x}$ represents the gradient value of a certain pixel of the image in the $x$-axis direction, $G_{y}$ represents the gradient value of a certain pixel of the image in the $y$-axis direction, and $p(x, y)$ represents the image value of the pixel at position $(x, y)$.

$$
\left\{\begin{array}{l}
G_{x}(x, y)=p(x+1, y)-p(x-1, y), \\
G_{y}(x, y)=p(x, y+1)-p(x, y-1) .
\end{array}\right.
$$

According to the theoretical research of the gradient feature extraction method, the generally selected pixel unit can be divided into 9 intervals. As shown in formula (7), the overall gradient value $G(x, y)$ of the image and the angle range $\rho(x, y)$ of the image gradient can be obtained by calculating the gradient of the image in the directions of the two coordinate axes. Then, according to the image gradient and angle range, the gradient direction histogram in the pixel unit is constructed as the gradient feature vector $[26,27]$.

$$
G(x, y)=\sqrt{G_{x}(x, y)^{2}+G_{y}(x, y)^{2}}, \rho(x, y)=\arctan \left[\frac{G_{y}(x, y)}{G_{x}(x, y)}\right] .
$$

In order to fully stimulate students' enthusiasm for the learning of moral education courses and improve the quality of teaching and course teaching effects, this article has added the function of intelligent learning reminders to the design of the mobile APP for moral education courses teaching. In the design of mobile teaching app, the interest correlation model is used to obtain mobile teaching resources which are more conducive to students' moral education teaching. The implementation process of this function is carried out in the data mining process of mobile teaching resources [28, 29]. The interest degree model is a screening and improvement of the association rules obtained by data mining. The generation of interest degree association rules is to use mathematical statistical knowledge to filter the interest degree value $\operatorname{corr}(x, y)$ in the association rules generated by existing data mining.

$$
\operatorname{corr}(x, y)=\frac{p(x, y)}{p(x) p(y)}=\frac{p(y \mid x)}{p(y)} .
$$

The numerator and denominator in formula (8) are the probability of the occurrence of the corresponding data item set, where $p(y \mid x)$ represents the probability of the occurrence of item set $y$ when item set $x$ appears and $\operatorname{corr}(x, y)$ reflects the correlation between item set $x$ and item set $y$. The greater the $\operatorname{corr}(x, y)$ value, the closer the connection between the items, and the strong association rules with the interest degree value less than 1 can be removed accordingly. The mobile teaching resource data collected through this kind of interest degree association rules can better cater to students' learning interests.

\subsection{Effectiveness Test of Mobile Application in Moral Edu-} cation Course Teaching. This paper sets up the application research experiment of mobile APP in moral education curriculum teaching and analyzes the application effect of mobile APP in moral education curriculum teaching through independent sample $t$-test and chi-square test. The principle of this method is to use the properties of mean $\bar{X}$, variance $S$, and statistics $T$ to preprocess the experimental data to improve the accuracy of the experiment. Studies have shown that many phenomena in life after a large number of random experiments are statistically approximated to obey the normal distribution. This article uses the most important sample parameters $\bar{X}$ and $S$ in the normal distribution to reflect the overall characteristics of the data and further introduces the laws of these data hiding. The statistic $T$ is used to detect outliers in the experimental data, which is the main principle of the independent sample $t$-test. If the calculated statistic of the sample data is greater than the standard value, such data should be classified as abnormal data, so it is also an abnormal data exclusion method.

$$
\bar{X}=\frac{1}{n} \sum_{i=1}^{n} x_{i}, S=\sqrt{\frac{1}{n} \sum_{i=1}^{n}\left(X_{i}-\bar{X}\right)^{2}}, T=\frac{\left(X_{i}-\bar{X}\right)}{S}, \quad(i=1,2, \ldots, n) .
$$

In formula (9), $X$ is the data reference value, $n$ is a constant, $i=1$ is the summation criterion, and $T$ and $S$ are the restrictive words, respectively, and formula (9) represents the effectiveness of classroom learning, especially the mobile phone APP applied to the effectiveness of moral education 
classroom teaching. In this type of the experimental effectiveness test, the most commonly used method is hypothesis testing. Assuming that the selected students come from the secondary vocational college students' moral education curriculum learning situation obey some expected distribution or regular characteristics, based on the actual collected student survey data, nonparametric hypothesis testing can be performed [30]. Its main principle is that when the number of samples $n$ tends to infinity, the population from which the sample comes will approximately obey the distribution of the sample, and then the chi-square test can be used to analyze the effectiveness of the mobile APP in the teaching of moral education courses. The specific test method is calculated as shown in the following formula:

$$
\chi^{2}=\sum_{i=1}^{n}\left[\frac{\left(f_{0}-f_{e}\right)^{2}}{f_{e}}\right] \text {. }
$$

\section{Investigation on the Application of Mobile APP in Moral Education Course Teaching}

3.1. Survey Objects. The experimental subjects in this study were randomly selected 320 teachers and students of moral education courses in secondary vocational colleges, including 80 moral education teachers and 240 students in school. This experiment uses face-to-face interviews, questionnaire surveys, telephone interviews, and other survey methods to investigate the teaching situation of moral education courses in secondary vocational colleges. Among all the surveyed individuals, 80 were in face-to-face interviews, 200 were in questionnaire surveys, and 80 were in telephone interviews. From this, we can see that questionnaire surveys are the mainstay. In the specific data collection and situation investigation, this article has made some improvements to the questionnaire survey and other methods to avoid direct and blunt question and answer methods that will give students the feeling of privacy leakage and get untrue answers. Due to the long survey period and the complicated teaching situation, it is difficult to accurately present data, so data collection is more difficult. This article distributed 360 questionnaires to teachers and students of moral education courses in secondary vocational colleges. Among them, 320 valid questionnaires were returned, and the effective response rate of the questionnaires was $88.9 \%$. This article mainly focuses on the investigation and statistics of the moral education curriculum teaching of moral education teachers of different genders and educational backgrounds and the students of all grades in secondary vocational colleges and the learning enthusiasm, learning ability, and moral education curriculum performance after using mobile APP teaching. Then, through interviews with teachers and students, we discussed the attitudes and views on the application of mobile APP-assisted moral education curriculum teaching and put forward some suggestions for improvement of moral education curriculum teaching methods.

3.2. Experimental Process and Questionnaire Design. This experiment is mainly divided into an experimental group and a control group. Questionnaire survey refers to the method of collecting information by formulating detailed and thorough questionnaires and asking respondents to answer accordingly. The so-called questionnaire is a set of questions related to the research objectives or a question form prepared for investigation, also known as a questionnaire. It is a common tool used by people to collect information in social survey research activities. Investigators use this tool to accurately and concretely measure the process of social activities and apply sociological statistical methods to describe and analyze quantities to obtain the required survey data. The experimental group collects and sorts out the data of the moral education course teaching situation of various secondary vocational colleges through mobile APP and other different methods and selects accurate and effective data to classify for subsequent analysis. The control group is to set up data on the teaching situation of moral education courses that do not use mobile APP, conduct surveys and statistics on these data, compare and analyze the data with the experimental group, study the influence and role of mobile APP in moral education curriculum teaching, and find out the current moral education curriculum teaching methods. There are four main types of questions in the design of the questionnaire, which are the conditions for the application of mobile APP to assist the teaching of moral education courses, the current situation of the teaching of moral education courses for teachers and students, students' attitudes and attitudes towards the application of mobile APP teaching, and the new teaching of the mobile APP teaching by parents as well as parents' acceptance and awareness of the mobile APP teaching model, and each type of question has 10 subquestions. This experiment is mainly divided into four steps. The first is to collect data on the teaching situation of moral education courses in secondary vocational colleges through various survey methods and related research documents. The second is to use statistical methods to analyze the collected data. The third is to take countermeasures to apply mobile APP to the application process of the improved moral education curriculum teaching method and use nonparametric tests to verify the effect and influence of these improvement measures on moral education curriculum teaching. Fourth, based on the experimental results and comprehensive data analysis of the teaching method using mobile APP, some regular characteristics and empirical conclusions of moral education curriculum teaching are drawn, hoping to bring inspiration to moral education curriculum teaching and promote the further development of moral education teaching.

3.3. Survey Data Processing and Error. The survey data in this article are mainly divided into two parts, which are the data of the current situation of moral education curriculum teaching before the application of mobile APP-assisted moral education teaching experiment and the data of the application of different teaching methods for moral education curriculum teaching control experiments. The data processing and error analysis of this experiment are processed by SPSS20.0 software. For the statistical data of the 
experimental results, the analysis of variance and nonhomogeneity of variance are used to test the accuracy and error of the results. This method uses $\alpha$ to represent all the significant levels between the experimental data $0-1$, and the test level can reach $\alpha=0.05$. In the data of the entire experimental group, excluding the influence of other factors, the data under the change of a single factor are analyzed and compared with the average value, and then the error test is carried out. For a set of experimental data, the number of data under a factor level that needs to be studied is denoted as $n$, and the error is MSE; then, the LSD test formula is shown in the following equation:

$$
L=\sqrt{\operatorname{MSE}\left(\frac{1}{n_{i}}+\frac{1}{n_{j}}\right)} .
$$

In the experiment, according to the different degrees of freedom of the variables, if the difference between the experimental group and the control group of group $k$ is to be tested, the analysis of variance heterogeneity is generally used to test, and Dunnett's test formula is shown in the following equation:

$$
s_{E}^{2}=\operatorname{MSe}\left(\frac{1}{n_{i}}+\frac{1}{n_{j}}\right), \quad D=\frac{\left(\bar{X}_{k}-\bar{X}_{0}\right)}{s_{E}^{2}} .
$$

In formula (12), $\bar{X}_{k}$ represents the data mean of the experimental group of group $k, X_{0}$ represents the mean of the experimental data of its control group, and MSe represents the mean error variance. This test method can make the mean of multiple experimental groups and one control group. Multiple comparisons of differences are used in this study to verify the conclusions drawn from the experimental results. All the above research studies are carried out in the teaching of moral education courses in some secondary vocational colleges. Therefore, our research results are also based on some secondary vocational colleges. All the research results are listed below.

\section{Discussion on the Application of Mobile APP in Moral Education Course Teaching}

4.1. Investigation on the Application Status of Mobile APP in Moral Education Course Teaching. In order to study the influence of mobile APP on the teaching of moral education courses, this article conducted a questionnaire survey on 340 teachers and students of moral education courses in secondary vocational colleges. The basic information of teachers and students participating in the survey is shown in Table 1. Among them, there are a total of 80 moral education teachers of different educational backgrounds and different genders, and 240 students are studying moral education courses. Among them, the moral education teachers are mainly undergraduates. There are 45 undergraduate moral education teachers, accounting for $52.50 \%$ of the interviewed moral education teachers.

According to the basic situation of moral education curriculum teaching in secondary vocational colleges, this article separately investigated the teaching methods of moral education curriculum on some teachers, students, and students' parents. The survey results are shown in Figure 1. Teachers are represented in red, students are represented in yellow, and parents are represented in pink. The three different color sections correspond to the five teaching modes. Most teachers and parents hope that students will learn moral education courses through teacher teaching and textbook reading, while students are more inclined to video learning and autonomous learning. Self-control is a Chinese word that means the ability of individuals to control and regulate their thoughts, feelings, and behavior. He is good at motivating himself to complete every decision he makes and is good at suppressing his desires, motivations, behaviors, and emotions that are not in line with the established goals. Self-control is an important sign of strength. The opposite is willfulness. Wayward people have an indulgent attitude towards themselves, their words and deeds are unrestrained, and they do not consider the consequences of their actions and the influence of the state of affairs. Therefore, the difference in the strength of self-control will easily lead to deviations in the effect of the teaching APP on the individual's use.

4.2. Cognitive Attitudes of Teachers and Students to Mobile Application in Moral Education Curriculum Teaching. This article also investigated the cognitive attitudes of teachers, students, and parents of secondary vocational colleges to the application of mobile APP in the teaching of moral education courses. The results of the survey are shown in Figure 2. Most of the parents of students expressed their strong opposition to students learning moral education courses through mobile APP mainly because they were worried that their children would be addicted to it. However, most teachers said that whether to use mobile APP for moral education curriculum teaching has no significant impact and hold a neutral attitude. Students at school are very eager to learn moral education courses through mobile APP; they think this learning method is more interesting. The author has carefully considered the neutral attitude of the teachers and the welcome attitude of the students. On the whole, the author also welcomes the use of mobile APP for moral education courses. This will not only increase the enthusiasm of students in class but also improve the efficiency of class.

4.3. Students' Performance in Moral Education Courses Using Mobile Apps. This article makes statistics on the students' moral education curriculum learning conditions that participated in the control experiment, and the statistical results are shown in Table 2. Among them, the experimental class and the control class each have 50 students. The data SD represents the standard deviation of student performance, and the data $T$ and $P$ represent the level test indicators of the experimental data sample $t$-test. The statistical content of the experimental results includes students' learning ability and learning enthusiasm.

According to the survey of the abovementioned teaching methods, this article conducts further surveys and statistics on the arrangement of moral education courses in secondary 
TABLE 1: Basic statistics of teachers and students in moral education courses.

\begin{tabular}{|c|c|c|c|c|c|c|}
\hline \multirow{2}{*}{ Type } & \multicolumn{3}{|c|}{ Moral education teachers } & \multicolumn{3}{|c|}{ School students } \\
\hline & Classification & Number & Proportion (\%) & Classification & Number & Proportion (\%) \\
\hline \multirow{2}{*}{ Gender } & Male & 35 & 43.75 & Male & 140 & 58.33 \\
\hline & Female & 45 & 53.25 & Female & 100 & 41.67 \\
\hline \multirow{3}{*}{ Education } & Junior & 29 & 36.25 & First grade & 88 & 36.67 \\
\hline & Bachelor & 42 & 52.50 & Second grade & 107 & 44.58 \\
\hline & Masters & 9 & 11.25 & Third grade & 45 & 18.75 \\
\hline Total & Sum & 80 & 100 & Sum & 240 & 100 \\
\hline
\end{tabular}

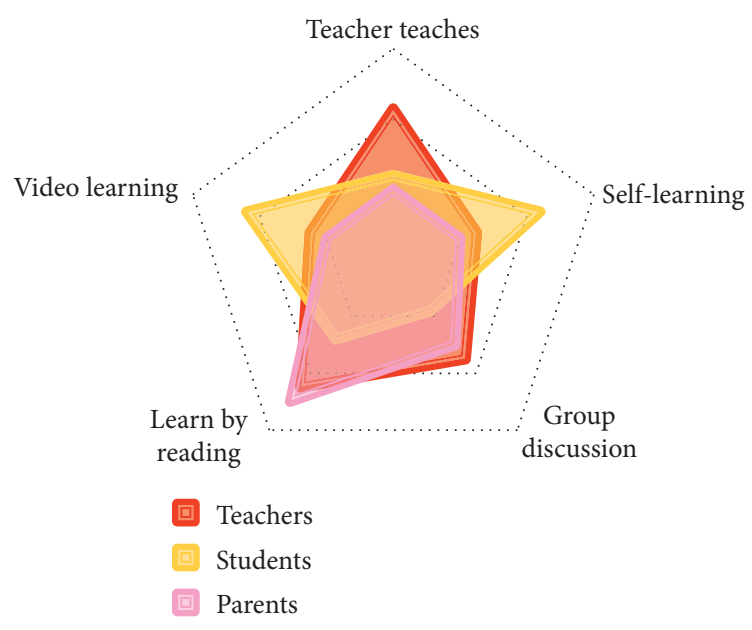

Figure 1: Views of teachers, students, and parents on the teaching format.

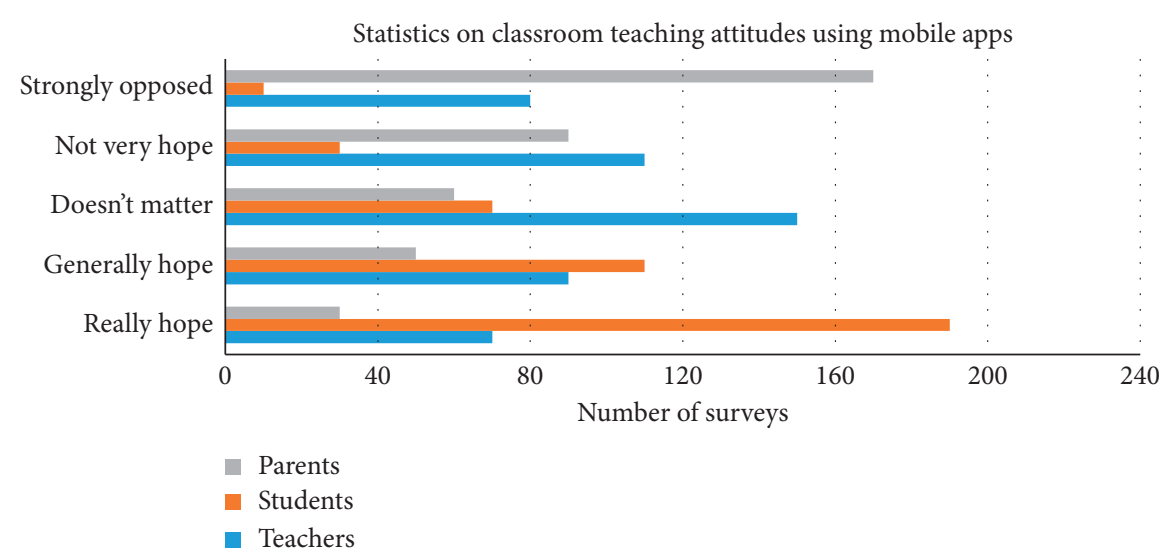

FIGURE 2: Statistics on classroom teaching attitudes using mobile apps.

TABLE 2: Comparative results of moral education course teaching experiment.

\begin{tabular}{lcccccc}
\hline Item & Class & Number & Mean & SD & $T$ & $P$ \\
\hline \multirow{2}{*}{ Learning enthusiasm } & Experimental & 50 & 32.667 & 2.796 & 1.256 & 0.214 \\
& Control & 50 & 31.825 & 2.574 & 4.235 & 0.008 \\
\hline \multirow{2}{*}{ Learning ability } & Experimental & 50 & 45.468 & 2.918 & -0.223 & 0.824 \\
& Control & 50 & 42.176 & 3.267 & 0.312 & 0.756 \\
\hline
\end{tabular}




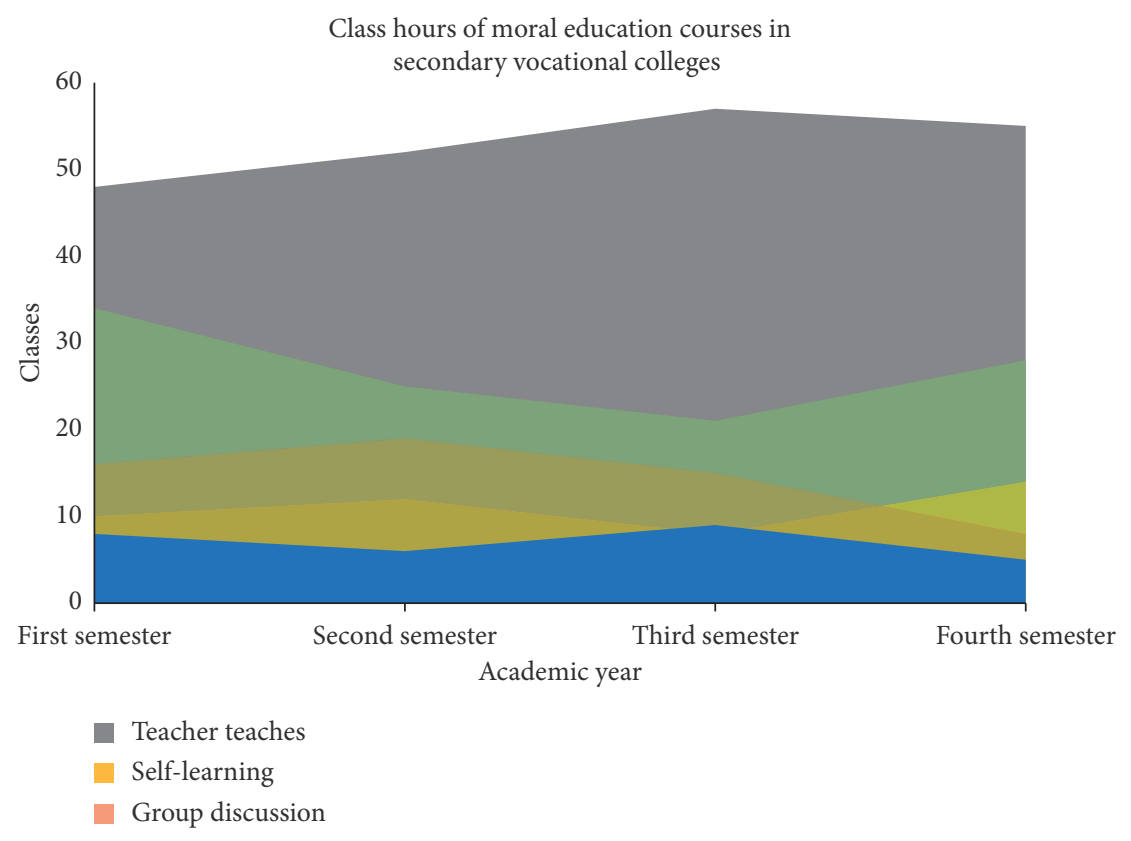

Figure 3: Class hours of moral education courses in secondary vocational colleges.

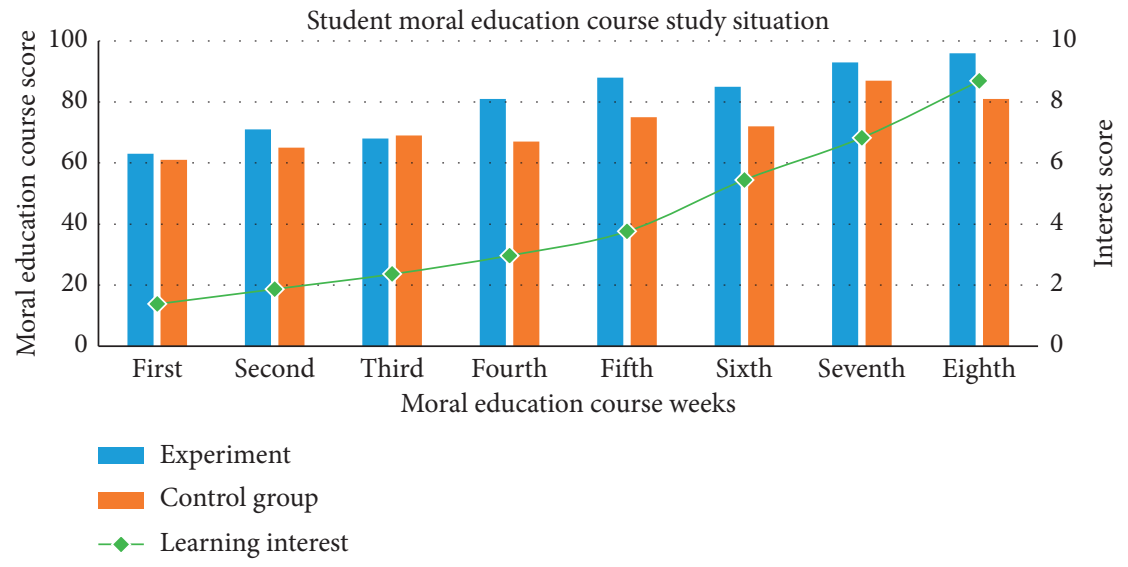

FIgURE 4: Student moral education course study situation.

vocational colleges. The results of the survey are shown in Figure 3. The time arrangement for students' moral education courses is mainly taught by teachers. In the two academic years of moral education courses, the number of moral education courses has reached 58 class hours, while the video learning schedule is almost close to zero.

\subsection{Influence of Mobile Applications on the Learning Efficiency} and Enthusiasm of Students in Moral Education Courses. At the end of the experiment, this article counts the moral education curriculum scores and learning interests of the experimental class students who use mobile APP to learn moral education courses in the control experiment and the control class students who learn moral education courses through traditional teachers. As shown in Figure 4, the grades of students learning moral education courses through mobile APP have improved significantly faster and more steadily, and their interest in learning is also increasing, while the grades of moral education courses of students in the control class have fluctuated and their interest in learning is not high.

\section{Conclusions}

Through investigation and analysis, this article briefly talks about the importance of moral education teaching to student education in secondary vocational colleges and the current status of moral education curriculum teaching. It is found that the moral education curriculum teaching in secondary vocational colleges has the following problems. Firstly, from a formal point of view, the teaching process of moral education courses in some secondary vocational colleges only depends on the results of the courses and does not explore the meaning of moral education in depth to help students establish a correct and positive outlook on life and morality. The second is that some moral education teachers think that moral education courses are not knowledge subjects, which 
do not take up too much class hours and are not very helpful to students. The third is the lack of some moral education teaching theoretical guidance and high-quality moral education teaching resources and teaching environment. Most students learn moral education courses based on the teacher's narration in the textbooks but do not have a deep understanding of the meaning of moral education courses.

As we all know, the application of mobile APP has brought people a large amount of data resources, and the graphical interface has attracted more students' interest in learning. Based on the difficulties faced by moral education courses, this paper proposes that the application of mobile APP to assist moral education courses can provide students with more mobile teaching resources and high-quality teaching environment, which can better cater to students' learning interests and improve the quality of moral education courses. Mobile APP can also combine advanced information technologies such as VR to create a good teaching environment, allowing students to have an immersive learning experience.

Due to the continuous advancement of information technology, it is not far away for mobile APP to enter the teaching of moral education courses. However, it also brings some undesirable effects, such as students easily addicted to it. Due to the limited education and academic level of the author, the research in this article has no constructive improvement measures for the adverse effects of these mobile apps entering the teaching classroom. It is hoped that the future research on the application of mobile APP to the teaching of moral education courses can explore in-depth from the directions of how to avoid the adverse effects of mobile APP on students and improve the quality of moral education teaching in combination with other teaching methods. Although the teaching APP can be used well in the actual classroom, it is still not enough to achieve particularly good results. In actual applications, the teaching APP will also have problems such as instability and slow software updates. So, this is the general direction of our further in-depth research.

\section{Data Availability}

This article does not cover data research. No data were used to support this study.

\section{Conflicts of Interest}

The authors declare that they have no conflicts of interest.

\section{Acknowledgments}

This work was supported by Research and Practice of Education Statistics Platform Construction Based on Teaching Quality Assurance Construction System (Information Assurance Scientific Research Project of Shaanxi Provincial Department of Education in 2020), item No. 20JX002 and Research on Building Branding on Connotation Development by Xi'an Fanyi University, item No. 2020Z01. This work was supported by Subject of Hunan Social Science Achievement Appraisal Committee (XSP19YBC116).

\section{References}

[1] C. Li and H. Jianbin, "Application of mobile teaching mode based on MosoTeach: benefits and challenges," International Journal of Applied Linguistics \& English Literature, vol. 8, no. 3, pp. 138-144, 2019.

[2] S. So, "Mobile instant messaging support for teaching and learning in higher education," The Internet and Higher Education, vol. 31, no. 10, pp. 32-42, 2016.

[3] P. F. Torres, A. F. P. Costa, V. L. Chaar Jr et al., "A mobile educational tool designed for teaching and dissemination of grid connected photovoltaic systems," Computers \& Electrical Engineering, vol. 76, no. 5, pp. 168-182, 2019.

[4] M. Halaweh, "Using mobile technology in the classroom: a reflection based on teaching experience in uae," Tech Trends, vol. 61, no. 3, pp. 1-5, 2017.

[5] R. P. Ponte, L. L. O. Sanders, A. A. Peixoto Jr, M. Kubrusly, and E. Marçal, "Development and usability assessment of a mobile application for neuroanatomy teaching: a case study in Brazil," Creative Education, vol. 10, no. 3, pp. 600-609, 2019.

[6] C. H. Pereira and R. Terra, "A mobile app for teaching formal languages and automata," Computer Applications in Engineering Education, vol. 26, no. 5, pp. 1742-1752, 2018.

[7] J. Landicho, "Hortari: a gamification application for engaged teaching and learning in higher education," Journal of e-Learning and Knowledge Society, vol. 13, no. 1, pp. 182-187, 2017.

[8] Y. Turkan, R. Radkowski, A. Karabulut-Ilgu, A. H. Behzadan, and A. Chen, "Mobile augmented reality for teaching structural analysis," Advanced Engineering Informatics, vol. 34, no. 10, pp. 90-100, 2017.

[9] B. Klímová, "Mobile phones and/or smartphones and their apps for teaching English as a foreign language," Education and Information Technologies, vol. 23, no. 3, pp. 1091-1099, 2018.

[10] P. Cao, "Research on mobile APP-based interpreting teaching mode," Revista de la Facultad de Ingenieria, vol. 32, no. 16, pp. 756-760, 2017.

[11] J. Wang, F. Gao, J. Li et al., "The usability of WeChat as a mobile and interactive medium in student-centered medical teaching," Biochemistry and Molecular Biology Education, vol. 45, no. 5, pp. 421-425, 2017.

[12] B. Zhang, "Research on framework design of English mobile teaching system in higher vocational colleges based on android platform," Boletin Tecnico/Technical Bulletin, vol. 55, no. 15, pp. 174-181, 2017.

[13] C. Gao and J. Wang, "Mobile teaching of digital mapping based on the WeChat official account admin platform," International Journal of Emerging Technologies in Learning, vol. 12, no. 7, pp. 23-28, 2017.

[14] D. Xu, "Research on new English mobile teaching mode under the impact of mobile Internet age," Open Journal of Social Sciences, vol. 07, no. 5, pp. 109-117, 2019.

[15] N. Merayo, I. Ruíz, J. Debrán et al., “AIM-Mobile Learning Platform to enhance the teaching-learning process using smartphones," Computer Applications in Engineering Education, vol. 26, no. 5, pp. 1753-1768, 2018.

[16] S. Ketabi and S. Kavoshian, "Innovative technology in English language teaching: the utility of mobile social network sites to improve teacher education," English Language Teaching, vol. 11, no. 1, pp. 39-67, 2017.

[17] B. J. Mackay, J. Anderson, and T. Harding, "Mobile technology in clinical teaching," Nurse Education in Practice, vol. 22, no. 9, pp. 1-6, 2017. 
[18] H. Hamidi and M. Jahanshahifard, "The role of the Internet of things in the improvement and expansion of business," Journal of Organizational and End User Computing, vol. 30, no. 3, pp. 24-44, 2018.

[19] F. AlTameemy, "Mobile phones for teaching and learning," Journal of Educational Technology Systems, vol. 45, no. 3, pp. 436-451, 2017.

[20] H. Richards and S. L. Watson, "Moral education for structural change," International Journal of Contemporary Education, vol. 2, no. 2, pp. 52-57, 2019.

[21] M. Zhou, Y. Wang, Z. Tian, Y. Lian, Y. Wang, and B. Wang, "Calibrated data simplification for energy-efficient location sensing in Internet of things," IEEE Internet of Things Journal, vol. 6, no. 4, pp. 6125-6133, 2019.

[22] Y. Yao, "Application of flipped classroom teaching mode based on MOOC in modern educational technology teaching," Journal of Computational and Theoretical Nanoscience, vol. 14, no. 2, pp. 1075-1078, 2017.

[23] E. Mohamed, "The relation of artificial intelligence with Internet of things: a survey," Journal of Cybersecurity and Information Management, vol. 1, no. 1, pp. 30-24, 2020.

[24] Z. Li, S. W. Tang, L. P. Zhao et al., "Exploration and practice of the integrated problem-based learning teaching mode in public health," Zhonghua Yu Fang Yi Xue Za Zhi, vol. 50, no. 4, pp. 367-369, 2016.

[25] O. A. H. Jones, M. Spichkova, and M. J. S. Spencer, "Chirality2: development of a multilevel mobile gaming app to support the teaching of introductory undergraduate-level organic chemistry," Journal of Chemical Education, vol. 95, no. 7, pp. 1216-1220, 2018.

[26] Z. Lv and K. Amit, "Big data analysis of Internet of things system," ACM Transactions on Internet Technology (TOIT), vol. 21 , no. 2, pp. 1-15, 2020.

[27] Z. Lv, R. Lou, J. Li, A. K. Singh, and H. Song, "Big data analytics for $6 \mathrm{G}$-enabled massive Internet of things," IEEE Internet of Things Journal, vol. 8, no. 7, pp. 5350-5359, 2021.

[28] S. Tu, X. Yan, K. Jie, M. Ying, and C. Huang, "WeChat: an applicable and flexible social app software for mobile teaching," Biochemistry and Molecular Biology Education, vol. 46, no. 5, pp. 555-560, 2018.

[29] W. Ji, J. Xu, H. Qiao, M. Zhou, and B. Liang, "Visual IoT: enabling Internet of things visualization in smart cities," IEEE Network, vol. 33, no. 2, pp. 102-110, 2019.

[30] S. Al-Rubaye, E. Kadhum, Q. Ni, and A. Anpalagan, "Industrial Internet of things driven by SDN platform for smart grid resiliency," IEEE Internet of Things Journal, vol. 6, no. 1, pp. 267-277, 2019. 